\title{
Emerging Therapies in Ethnic Population
}

\author{
Shah Murad ${ }^{*}$, Abdul Ghaffar Mastoi ${ }^{2}$, Seema Saif Khoso ${ }^{3}$, Salman Iftikhar ${ }^{4}$, AQ Arain ${ }^{5}$, Jamila Shah ${ }^{6}$ \\ ${ }^{1}$ Department of Pharmacology, Islamabad Medical College, Pakistan \\ ${ }^{2}$ Community Welfare Officer, IMDC Islamabad, Pakistan \\ ${ }^{3}$ Gynecologist, IMDC/DANTH, Pakistan
}

${ }^{4}$ Associate Professor of Pharmacology, Pakistan

${ }^{5}$ Assoc Prof of Pharmacology, HBS Medical College, Pakistan

${ }^{6}$ Clinical Psychologist, Bahria University, Pakistan

*Corresponding author: Shah Murad, Department of Pharmacology IMDC, Islamabad-Pakistan

\begin{abstract}
Some of the most important medicinal plants with hypoglycemic properties according to reliable clinical and laboratory evidence, and also touched on the medicinal plants that are prescribed in Pakistani traditional medicine, for the treatment of diabetes. The information in this article was obtained from the eligible articles retrieved using the search terms diabetes mellitus, medicinal plants, type 1 diabetes and medicinal plants, type 2 diabetes and medicinal plants, and the effect of extract and essential oil of medicinal plants affecting diabetized tissues in the human body. Regarding type-II Diabetes mellitus at least initially, and often throughout their lifetime, these patients do not need insulin treatment to survive. Metformin is oral antidiabetic drug having lesser morbid effects as compared to other oral antidiabetic agents. We have compared hypoglycemic potential of herbal hypoglycemic agent Figs or INJEER with Metformin. It was single blind correlational research conducted at Jinnah Hospital Lahore-Pakistan from April to October 2018. Fifty diabetic type-II patients of were selected for research. Approved and explained consent was taken by all patients. They were divided in two groups, 25 patients in each group. Group-I patients were advised to take 250 mg Metformin thrice daily for two months. Group-II patients were advised to take 10 grams of Injeer (Figs) in three divided doses for two months. Their base line fasting blood glucose level was taken and kept in record. They were advised to visit the OPD of the hospital fortnightly. They were also advised to check their fasting plasma glucose level daily at the morning by using Glucometer (provided by Acon Pharmaceutics Ltd). After two months when results were compiled and statistically analyzed, it was observed that Metformin decreased blood sugar level $27.6 \%$ and Figs decreased $13.5 \%$. It was concluded from the study that Figs can decrease blood glucose level significantly, but when compared to Metformin, this change is about half fraction of the Metformin.
\end{abstract}

\section{Introduction}

There are currently more than 150 million people with diabetes across the globe, which seems to reach 300 million by 2025. In the absence of proper treatment, cardiac, vascular, neurological, and renal damage and neuropathy may occur. Treatment includes diet, exercise, and medication. Currently, the main and effective treatment for diabetes is the use of insulin and hypoglycemic drugs, but these compounds also have many adverse side effects. Medicinal plants have a long history of usage and today, they are being extensively used for various diseases. There are three major types of diabetes: type 1 diabetes, type 2 diabetes, and gestational diabetes [1]. All types of diabetes mellitus have something in common. Normally,

body breaks down the sugars and carbohydrates eat into a special sugar called glucose. Glucose fuels the cells in body. But the cells need insulin, a hormone, in bloodstream in order to take in the glucose and use it for energy. With diabetes mellitus, either body doesn't make enough insulin, it can't use the insulin it does produce, or a combination of both [2]. Since the cells can't take in the glucose, it builds up in blood. High levels of blood glucose can damage the tiny blood vessels in kidneys, heart, eyes, or nervous system. That's why diabetes -- especially if left untreated -- can eventually cause heart disease, stroke, kidney disease, blindness, and nerve damage to nerves in the feet [3]. Currently, six classes of oral antidiabetic drugs (OADs) are available: biguanides (e.g., 
metformin), sulfonylureas (e.g., glimepiride), meglitinides (e.g., repaglinide), thiazolidinediones (e.g., pioglitazone), dipeptidyl peptidase IV inhibitors (e.g., sitagliptin), and $\alpha$-glucosidase inhibitors (e.g., acarbose) [4]. Metaformin marketed under the trade name Glucophage among others, is the first-line medication for the treatment of type 2 diabetes. This is particularly true in people who are overweight. It is also used in the treatment of polycystic ovary syndrome. Limited evidence suggests metformin may prevent the cardiovascular disease and cancer complications of diabetes. It is not associated with weight gain. It is taken by mouth [5]. Metformin is generally well tolerated. Metformin is in the biguanide class. It works by decreasing glucose production by the liverand increasing glucose use by body tissues [6-9]. Fig is a tree. The fruit is commonly eaten. The fruit and leaves are used to make medicine [10]. Raw figs are a good source (14\% of the Daily Value, DV) of dietary fiber per 100 gram serving (74 calories), but otherwise do not supply essential nutrients in significant content. In a 100gram serving providing 229 calories, dried figs are a rich source (> 20\% DV) of dietary fiber and the essential mineral, manganese (26\% DV), while several other dietary minerals are in moderate-to-low content [11]. Figs contain diverse phytochemicals, including polyphenols such as gallic acid, chlorogenic acid, syringic acid, (+)-catechin, (-)-epicatechin and rutin. Fig color may vary between cultivars due to various concentrations of anthocyanins, with cyanidin-3O-rutinoside having particularly high content. Many plants from different parts of the world have been investigated for antidiabetic effects $[12,13]$.

\section{Patients \& Methods}

Design of research work was correlational, and was conducted at Jinnah Hospital, Lahore from April to october 2018. Fifty diabetic patients (Diabetes Mellitus type-II) were selected from Jinnah hospital to conduct research study. Inclusion criteria was age limit from 25 to 70 years of both gender, male and female whose hyperglycemia was controlled and moderate in state. We excluded those diabetic patients whose hyperglycemia was uncontrolled, unstable, fragile due to use of allopathic or herbal hypoglycemic agents. Patients were divided in two groups. Group-I (25 diabetic patients) was advised to take $250 \mathrm{mg}$ of Tablet Glucophage $250 \mathrm{mg}$ (Metformin) half an hour before taking meal, thrice daily for two months. Group-II patients (25 diabetic patients) were advised to take Injeer (Figs) 10 grams daily in three divided doses half an hour after each meal for two months. Their baseline fasting glucose level was determined by Glucometer (On Call Extra made by ACON Lab 1190059) at start of research work. They were advised to check and keep in record their fasting blood glucose level every day early in the morning. They were advised to take their normal meal without any supplement or high glucose-contained baked or high glucose containing natural fruits. They were advised to come at hospital for follow up or any query regarding drug compliance. Data were expressed as the mean \pm SD and " $t$ " test was applied to determine statistical significance as the difference. A probability value of $<0.01$ was considered as significant and $\mathrm{P}<0.001$ was considered as highly significant.

\section{Results}

Results of treatment with two different drugs on fasting blood glucose of DM-II patients are shown in following table, which are self-explanatory. Table 1 explaining before and after treatment values, percentage change and statistical significance of diabetic patients with two different drugs.

Table 1: Explaining before and after treatment values, percentage change and statistical significance of diabetic patients with two different drugs.

\begin{tabular}{|c|c|c|c|c|c|}
\hline Tables Drug group & At day-0 & At day-60 & change & \% change & p-value \\
\hline Group-I (Metformin) $\mathrm{n}=23$ & $230.04 \pm 1.99$ & $166.66 \pm 2.05$ & 63.4 & 27.6 & $<0.001$ \\
\hline Group-II (Figs) $\mathrm{n}=25$ & $219.22 \pm 1.67$ & $189.67 \pm 1.04$ & 29.5 & 13.5 & $<0.01$ \\
\hline
\end{tabular}

KEY: All values were measured in $\mathrm{mg} / \mathrm{dl}$, Dose of Metformin was $250 \mathrm{mg}$ thrice daily, dose of Figs was 10 grams in three divided doses, $\mathrm{n}=$ sample size, $\mathrm{p}$-value $<0.01$ was considered as significant and $\mathrm{p}$-value $<0.001$ was considered as highly significant change.

\section{Discussion}

For diabetes in the absence of proper treatment, cardiac, vascular, neurological, and renal damage and neuropathy may occur. Treatment includes diet, exercise, and medication. Currently, the main and effective treatment for diabetes is the use of insulin and hypoglycemic drugs, but these compounds also have many adverse side effects. Medicinal plants have a long history of usage and today, they are being extensively used for various diseases. Allopathic medications are just for good survival of the patients victimized by diabetes mellitus. These drugs have adverse effects which can lead to less compliance of patients. Now a days herbal medications are going to replace allopathic drugs due to their ethnic related doctrine and having lesser adverse effects. In our research Metformin decreased fasting blood glucose $63.4 \mathrm{mg} /$ $\mathrm{dl}$ in two months therapy which is equal to $27.6 \%$ decrease. Bio statistically this change in mean values are highly significant which match with results of study conducted by Hubbard JK et al. [14] who proved almost same effects of Metformin on fasting blood sugar levels in 103 diabetic patients suffering from Diabetes Mellitus type-II. Dunn CJ et al. [15] described that Metformin interrupt carbohydrates absorption from gastrointestinal tract. Our results are in contrast with results of study conducted by Spiller HA et al. [16] who observed and proved only $24.8 \mathrm{mg} / \mathrm{dl}$ reduction in 22 diabetic male patients when Metformin was used at dose of $250 \mathrm{mg}$ twice daily for three weeks. This contrast in results may be due to less concentration of drug used. Hundal RS et al. [17] agrees with already accepted theory of Metformin's hypoglycemic mechanism that inhibition of hepatic gluconeogenesis is main cause for blood glucose level reduction. Triggle CR et al. [18] labelled Metformin drug as first choice hypoglycemic agent in type-II diabetic patients. 
In our research results Figs or Injeer decreased fasting blood sugar about $29.5 \mathrm{mg} / \mathrm{dl}$ in two months therapy in 25 diabetic patients of Type-II which is statistically significant decrease in the parameter. These results match with results of study conducted by Mawa S et al. [19] who proved that about $30.87 \mathrm{mg} / \mathrm{dl}$ of blood glucose may be decreased when Figs are used for three months with regular intake of this fruit with each meal i.e. thrice daily. C Perez et al. [20] proved almost same changes in fasting blood glucose in 117 diabetic patients suffering from Type-II DM. Perez C et al. [21] wrote that these fruits can lower fasting sugar level even more than this reduction proved, if used in enough amount and in researchcontrolled environment. Our results do not match with results of research work conducted by Serraclara A et al. [22] who proved very small amount of blood glucose reduction in 12 patients suffering from DM type-II, even they used $500 \mathrm{mg}$ of Metformin thrice daily for one month. Contrast in these results are or may be due to lesser exposure of drug and small sample size. Lyme WE et al. [23] warned in their research work's conclusion that Metformin can cause morbid effects if given concurrently with Insulin. He has encouraged to use Metformin with Figs without any fear of morbid hypoglycemia. Farzana K et al. [24] explained that various drug combination especially allopathic agent and medicinal plants can cause synergetic effects, so must be used with dose titration. Lujha MN et al. [25], Sarmanv J et al. [26] and Khursheed M et al. [27] have emphasized on meta analytic research on pharmacognosy and medicinal plants to get right and full therapeutic usefulness from these compounds. Diabetes mellitus is the most common chronic and metabolic disease characterized by an increase in glucose levels due to absolute or relative insulin deficiency. The disease is associated with eye, renal, cardiovascular, and neurological complications in the long term. This disease is also associated with symptoms such as polyuria, fatigue, weight loss, delayed wound healing, blurred vision, increases in urine glucose levels [28-32].

\section{References}

1. de Amorin A, Borba HR, Carauta JP (2009) Anthelmintic activity of the latex of Ficus species. J Ethnopharmacol 64(3): 255-258.

2. Kostapanos MS, Liamis GL, Milionis HJ, Elisaf MS (2010) Do statins beneficially or adversely affect glucose homeostasis. Curr Vasc Pharmacol 8: 612-631.

3. Lacher M, Hermanns Clausen M, Haeffner K, Brandis M, et al. (2005) Severe metformin intoxication with lactic acidosis in an adolescent. Eur J Pediatr 164(6): 362-365.

4. (2010) The Expert Committee on the Diagnosis and Classification of Diabetes Mellitus: Report of the Expert Committee on the Diagnosis and Classification of Diabetes Mellitus. Diabetes Care 20: 1183-1197.

5. Lipska KJ, Bailey CJ, Inzucchi SE (2011) Use of metformin in the setting of mild-to-moderate renal insufficiency. Diabetes Care 34(6): 1431-1437.

6. Carpenter MW, Coustan DR (2011) Criteria for screening tests for gestational diabetes. Am J Obstet Gynecol 144: 768-773.

7. Canal JR, Torres MD, Romero A, Perez C (2010) A chloroform extract obtained from a decoction of Ficus carica leaves improves the cholesterolaemic status of rats with streptozotocin- induced diabetes. Acta Physiol Hung 87(1): 71-76.

8. Liu A, Coleman SP (2009) Determination of metformin in human plasma using hydrophilic interaction liquid chromatography-tandem mass spectrometry. J Chrom B 877(29): 3695-3700.
9. NA Zeggwagh, A Moufid, A Khaldi, JB Michel, M. Eddouks (2010) Cardiovascular effects of Nigella sativa aqueous extract. Circulation 6 (8): 343-346.

10. DellAglio DM, Perino LJ, Kazzi Z, Abramson J, Schwartz MD, et al. (2009) Acute metformin overdose: examining serum pH, lactate level, and metformin concentrations in survivors versus nonsurvivors: a systematic review of the literature. Ann Emerg Med 54(6): 818-823.

11. Fantus IG, Brosseau R (2009) Mechanism of action of metformin: insulin receptor and postreceptor effects in vitro and in vivo. J Clin Endocrinol Metab. 63(4): 898-905.

12. Perez C, Canal JR, Campillo JE (2008) Hypotriglyceridaemic activity of Ficus carica leaves in experimental hypertriglyceridaemic rats. Phytother Res 13(3): 188-91.

13. Rubnov S, Kashman Y, Rabinowitz R (2010) Suppressors of cancer cell proliferation from fig (Ficus carica) resin: isolation and structure elucidation. J Nat Prod 64(7): 993-996.

14. Hubbard JK, Soman JT, Firka LU (2014) Type 2 diabetes and metformin. First choice for monotherapy: weak evidence of efficacy but well-known and acceptable adverse effects. Prescrire international 23(154): 269272 .

15. Dunn CJ, Mokar TY, Peters DH (2007) Metformin. A review of its pharmacological properties and therapeutic use in non-insulindependent diabetes mellitus. Drugs 49 (5): 721-49.

16. Spiller HA, Weber JA, Winter ML, Klein-Schwartz W, Hofman M, et al. (2010) Multicenter case series of pediatric metformin ingestion. Ann Pharmacother. December 34(12):1385-1388.

17. Hundal RS, Mekun HY, Inzucchi SE (2008) Metformin: new understandings, new uses. Drugs 63(18):1879-1894.

18. Triggle CR, Peten TR, Tungju MR, Ding H (2015) Metformin is not just an antihyperglycaemic drug but also has protective effects on the vascular endothelium. Acta physiologica 115(4): 227-229.

19. Mawa S, Husain K, Jantan I (2013) Phytochemistry of Fig: Traditional Uses and Biological Activities. Evid Based Complement Alternat Med 14(7): 4256-4259.

20. C Perez, E Domingues, MD Torres (2009) Hypoglycemic activity of an aqueous extract from Fig tree leaves in diabeteic patients. Pharmaceutical Biology 38(3): 181-186.

21. Perez C, Mahul K, Insur T, Dunminku Y (2009) A study on the glycaemic balance in diabetic patients treated with an aqueous extract of Ficus carica (fig tree) leaves. Phytotherapy Research 20(1): 82-83.

22. Serraclara A, Hawkins F, Perez C (2009) Hypoglycemic action of an oral fig-leaf decoction in type-I diabetic patients. Diabetes Res Clin Pract 39(1): 19-22.

23. lyme WE, Sen YS, Paralu YT (2008) Hypoglycemic action of an oral figleaf in type-II diabetic patients. Diabetes Research and Clinical Practice 39(1): 1200-1211.

24. Farzana K, Rukhsar M, Farhan K, Barkat S, Bilawal L (2016) New ways to treat health problems. Allo VS Alt Med 3(2): 66-69.

25. Lujha MN, Sarmanv BY, Fernhinn LL, Jololl TR (2014) World of Herbs 10(3): 375-379.

26. Sarmanv J, Helnev U, Erikjv C, Soothmj B (2012) Plants and therapeutics. J Med Bot 3(1): 333-338.

27. Khursheed M, Malook A, Barkat S (2014) Effects of plants on health. Medicinal Botany 4(2): 88-92.

28. Luija E, Yulsee C, Mawa S, Husain K, Jantan I (2016) Phytochemistry of Fig: Traditional Uses and Biological Activities. JMHR 22(1): 90-95.

29. Mahul K, Insur T, Dunminku Y, C Perez, E Domingues, et al. (2013) Hypoglycemic activity of an aqueous extract from Fig tree leaves in diabeteic patients. Pharmaceutical Biology 18(3): 112-116. 
30. Sarmanv BY, Fernhinn LL Perez AC, Mahul IK, Insur TI, et al. (2017) A study on the glycaemic balance in diabetic patients treated with an aqueous extract of Ficus carica (fig tree) leaves. Phytotherapy Research 23(8): 12-17.

31. Rukhsar M, Farhan K, Barkat S, Serraclara A, Hawkins F, et al. (2010) Hypoglycemic action of an oral fig-leaf decoction in type-I diabetic patients. Jou Med Herbs 13(5): 223-227.
32. lyme WE, Sen YS, Rukhsar M, Farhan K, Barkat S, et al. (2017) Hypoglycemic action of an oral fig-leaf in type-II diabetic patients. JHMCR 111(5): 67-73. (c) (i)

This work is licensed under Creative Commons Attribution 4.0 License

To Submit Your Article Click Here:

Submit Article

DOI: 10.32474/RRHOAJ.2019.04.000179

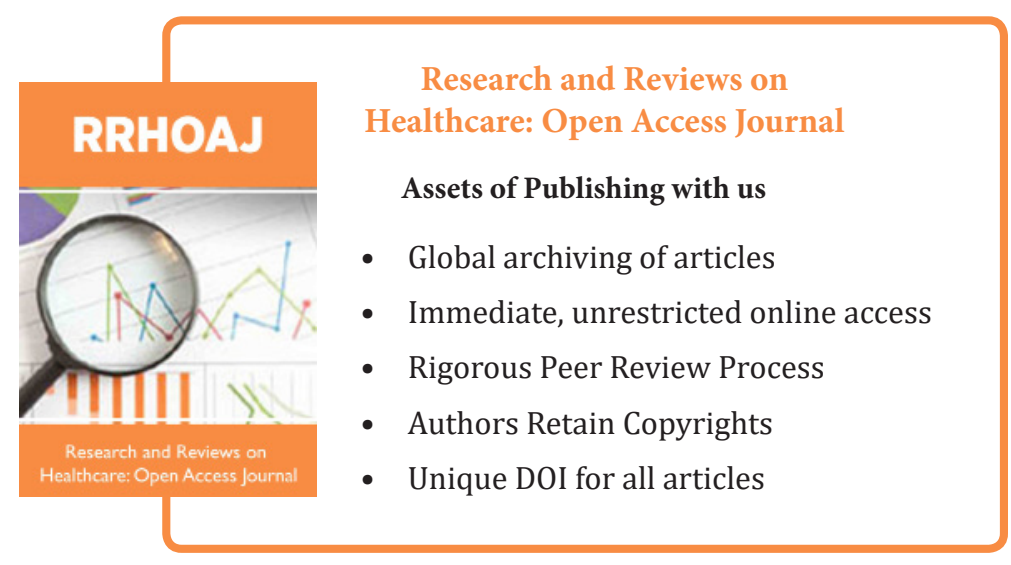

